\title{
ANALISIS PENGGUNAAN COMPLETION FLUID GARAM BERAT NITRAT SEBAGAI HOLE CLEANING DAN PENGARUHNYA TERHADAP ZAT ADITIF
}

\author{
Indriani Agustina, Bayu Satiyawira, Mulia Ginting \\ Fakultas teknologi kebumian dan energi, universitas trisakti \\ agustinai@yahoo.com
}

\begin{abstract}
Completion fluid is a fluid used in conducting operational completion, where the fluid used must be based on consideration of the formation characteristics for a particular well. Fluid selection is very important if the formation damage will be minimized. good complexion fluids can reduce solid content, absence of clay, solulable acid, dissolve in water and are used for operations such as perforation, cleaning wells and well control. The nitrate salts used are $\mathrm{CaNO} 3$ and NaNO 3 salts. Agarfluida complexes can function properly, so the fluid must always be controlled for its physical properties, which consist of fluid specific gravity, fluid rhology, filter rate, swell meter and $\mathrm{pH}$. The use of compound fluid is adjusted to the conditions of the formation that is being perforated such as formation rock formation conditions, and fluid content contained in the formation. This study will examine the use of fluid complexes from heavy salts of nitrates as hole cleaning and their effect on the additives used. It was concluded that the use of saline-complex fluid heavy with NaNO3 nitrate and its combination with the use of $\mathrm{CaCO} 3$ had the effectiveness to carry out hole cleaning activities with the results of Plastic Viscosity $23 \mathrm{cp}, 24 \mathrm{lbs} / 100 \mathrm{ft}$ Yield Point, $4.2 \mathrm{ml} / 30$ 'Filtrate, $\mathrm{pH} 7,41$, and Swellmeter 6\%.
\end{abstract}

Keywords: well control, non damaging, hole cleaning

\begin{abstract}
Abstrak
Fluida komplesi adalah fluida yang digunakan dalam melakukan operasional komplesi, dimana fluida yang digunakan harus didasarkan pada pertimbangan karakteristik pembentukan untuk sumur tertentu. Pemilihan fluida sangat penting jika kerusakan formasi yang akan diminimalkan. fluida komplesi yang baik dapat mengurangi kadar solid, tidak adanya clay, solulable asam, larut dalam air dan digunakan untuk operasi seperti perforasi, membersihkan sumur dan well control. Garam nitrat yang digunakan adalah garam $\mathrm{CaNO}_{3}$ dan $\mathrm{NaNO}_{3}$. Agarfluida komples dapat berfungs idengan baik, maka fluida tersebut harus selalu dikontrol sifat-sifat fisiknya, yang terdiri dari berat jenis fluida, rehologi fluida,laju tapisan,swellmeter dan $\mathrm{pH}$. Penggunaan fluida komplesi disesuaikan dengan kondisi formasi yang sedang diperforasi seperti batuan formasi kondisi formasi,dan kandungan fluida yang terdapat didalam formasi. Penelitian ini akan meneliti pemakaian fluida komplesi dari garam berat nitrat sebagai hole cleaning dan pengaruhnya terhadap zat aditif yang digunakan. Diperoleh kesimpulan bahwa pemakaian fluida komplesi garam berat nitrat $\mathrm{NaNO}_{3}$ dan perpaduannya dengan pemakaian $\mathrm{CaCO} 3$ memiliki keefektifan untuk melakukan kegiatan hole cleaning dengan hasil Plastic Viscosity $23 \mathrm{cp}$, Yield Point $24 \mathrm{lbs} / 100 \mathrm{ft}^{2}$, Filtrat 4,2 ml/30', pH 7,41, dan Swellmeter 6\%.
\end{abstract}

Kata kunci: well control, non damaging, hole cleaning

\section{Pendahuluan}

Setelah tahap ataupun proses pemboran selesai dilakukan, maka tahap selanjutnya adalah tahap produksi. Dimana pada tahap ini dibutuhkan fluida komplesi. Tahapan komplesi dilakukan pada setelah proses drilling dan sebelum dilakukannya produksi. Dalam pelaksanaan well completion berlangsung maka kondisi sumur tidak bisa dibiarkan kosong, maksudnya adalah jangan sampai kolom fluida yang sudah ada di sumur berkurang ataupun tidak seimbang dengan tekanan formasi. Karena bila terjadi kekosongan fluida atau tekanan formasi lebih besar dari pada tekanan hydrostatik maka dapat menyebabkan kick ataupun yang lebih parah blow out. Maka dari itu digunakan fluida komplesi untuk menjaga tekanan saat dilakukannya proses perforasi. 
(c) 2018 Pres Univ Press Publication, Indonesia

Tahapan pasca pemboran, yakni tahapan komplesi juga didesain untuk tetap menjaga kondisi formasi ini, antara lain dengan pemilihan penggunaan Completion Fluid yang tepat. Completion Fluid yang ideal adalah Completion Fluid yang tidak menimbulkan kendala operasional komplesi, tidak menimbulkan efek kerusakan formasi dan minim terhadap dampak kerusakan lingkungan.

Salah satu Completion Fluid yang saat ini mulai digunakan adalah Completion Fluid berbasis Nitrat. Saat ini sangat terbatas variasi completion fluid yang mampu memenuhi kualifikasi operasi, seperti: tidak korosif, kompatibeldengan production string, kompatibel dengan chemical penyemenan hingga efek terhadap lingkungan.

Completion fluid berbasis Nitrat ini merupakah salah satu alternatif completion fluid yang dikembangkan dari aplikasi nitrat sebagai pemberat non solid yang sebelumnya sudah digunakan sebagai lumpur.

Dengan keunggulan Completion Fluid berbasis nitrat ini dapat digunakan sebagai Hole cleaning yang akan diuji cobakan dengan garam berat nitrat $\mathrm{CaNO}_{3}$ ataupun $\mathrm{NaNO}_{3}$.

Sedangkan dalam fluida komplesi ini akan digunakan juga sebagai media Hole Cleaning dengan menggunakan sifat fisik yang perlu dipertimbangkan yaitu Rheology yang akan

diamati dengan PV dan YP yang mencapai target dengan densitas yang diinginkan agar dapat mengangkat debris dan proses hole cleaning dapat dilakukan. Dengan penambahan adiktif sebagai pemberat yaitu memakai $\mathrm{CaCO}_{3}$ sebagai acid solulable. Juga mencari garam diantara $\mathrm{Na}$ dan $\mathrm{Ca}$ yang akan mencapai komposisi dan sesuai target.

\section{Teori Dasar}

Salah satu isu pada operasional komplesi adalah formation damage. Kerusakan formasi ini akan semakin besar pada komplesi sumur-sumur eksploitasi (pengembangan) yang secara teoritis dibor untuk menghasilkan hidrokarbon sebagaimana sumur-sumur sekitarnya. Dalam hal ini membutuhkan sejenis fluida untuk tugas khusus setelah komplesi selesai dilakukan yang dapat mengurangi segala problem sumur yaitu completion fluid.

1. Mengimbangi tekanan formasi

Fungsi utama dari fluida komplesi adalah menstabilkan atau menyeimbangkan lubang sumur antara tekanan formasi dengan tekanan hidrostatis dari fluida komplesi tersebut supaya tidak terjadi kick ketika proses pergantian fluida sumur dari mud drilling dengan completion fluid.

2. Meinimalisir kerusakan formasi

Fluida komplesi yang digunakan pada suatu lapangan dapat berfungsi untuk membersihkan lubang bor dan formasi sekitar lubang bor dari sisa-sisa fluida komplesi dan semen komplesi. Sisa-sisa komplesi biasanya berbentuk padatan-padatan yang seandainya dibiarkan maka akan berakibat menyebabkan kerusakan formasi atau damage, hal ini yang nanti dapat mengurangi efisiensi dari kemampuan laju alir produksinya. Dan dalam penggunaannya mungkin dapat membersihkan sekitar lubang bor.

\section{Garam Berat Nitrat}

Garam berat adalah komponen utama dalam pembuatan fluida komplesi dan kerja ulang. Disamping itu dalam jumlah tertentu juga sering dicampurkan ke dalam system komplesi. Karakteristik fisika dan kimia dari garam berat atau fluida komplesi itu sendiri meliputi densitas, viskositas, stabilitas terhadap temperatur, komposisi kimia, faktor korosif $(\mathrm{pH})$, kompaktibilitas adiktif, kompaktibilitas formasi, kemampuan transportasi solid, dan kompaktibilitas dengan lingkungan.

\section{Pengaplikasian Fluida Sebagai Hole Cleaning}


Ini adalah fungsi yang sangat penting dari fluida komplesi, sisa dari hasil perforasi (Debris) cenderung menghambat proses selanjutnya, sehingga debris akan bertumpuk pada dasar lubang. Pencegahannya adalah mengurangi perbedaan tekanan yang terlalu tinggi dan aliran fluida komplesi yang merata ke seluruh lubang sumur sehingga debris dapat terangkat ke permukaan bersama dengan fluida komplesi.

Sifat dasar fluida komplesi juga tidak kalah penting dalam proses pengangkatan pasir, jika ada problem kepasiran pada formasi yang harus meliputi pada berat jenis (densitas) dan kekentalan (viskositas) harus dikendalikan sehingga dapat mengangkat debris ataupun pasir dengan sempurna. Fluida komplesi mengalir melalui tubing masuk ke pahat dan keluar melalui nozzle yang akan menimbulkan daya sembur yang sangat kuat sehingga dasar lubang bersih dari debris.

\section{Zat Aditif Yang Digunakan}

Didalam fluida komplesiselain terdiri atas komponen pokok seperti garam berat nitrat, maka ada material lain yang berfungsi mengontrol dan memperbaiki sifat-sifat fluida tersebut agar sesuai dengan formasi yang dihadapi selama Hole Cleaning. Berikut ini akan disebutkan beberapa komponen utama pencampuran fluida komplesi dengan additives yang bertujuan mengontrol berat jenis fluida komplesi, viskositas sebagai kekuatan fluida dalam pengangkatan debris, laju tapisan, $\mathrm{pH}$ dan swellmeter.

\section{Fresh Water}

Air merupakan komponen utama didalam system pembuatan fluida komplesi dan banyak digunakan dengansifatnya yang mudah didapat dan fasa kontinyu. Juga sebagai media pencampur antara berbagai media komposisi campuran fluida komplesi. Ada dua jenis air yaitu air tawar dan air asin (air laut), yang umum digunakan adalah air tawar.

\section{Viscosifier}

$X C D$ Polymer adalah polimer dengan berat molekul tinggi yang merupakan material viscosifier utama hasil modifikasi poli sakarida. XCD dapat digunakan dalam fresh water maupun salt water dan cocok dengan semua aditif fluida pengeboran water base. $X C D$ Polimer digunakan untuk memperoleh viskositas cairan pengeboran yang tinggi dengan kandungan padatan rendah. Selain itu, viskositas cairan pengeboran tetap hampir konstan sampai suhu $300^{\circ} \mathrm{F}$, dalam rentang pH 3 sampai 12 .

\section{Pac-L}

Pac- $L$ adalah polimer dengan berat molekul rendah yang dapat larut dalam air yang berasal dari selulosa. Dapat digunakan dalam segala jenis water base. Pac- $L$ berfungsi untuk mengurangi / mengendalikan API filtrate loss tanpa mengubah viskositas fluida, menstabilkan rheology, serta meningkatkan kualitas mud cake.

\section{HT-Stabilizer}

HT-stabilizer digunakan untuk memberikan control dan stabilitas reologi filtrasi dalam semua jenis pengeboran water base. Efektif sebagai penstabil fluida pengeboran serta mengurangi HTHP filtrate. Sangat efektif digunakan pada suhu lebih dari $250^{\circ} \mathrm{F}$.

\section{Calcium Carbonate}

Additive ini berguna untuk memperberat fluida komplesi, penambahan berat fluida komplesi digunakan untuk menahan tekanan formasi didasar lubang sumur dan juga sangat penting untuk menahan tekanan formasi pada lapisan shale. Sebagai dehydrator formasi dan menjaga ukuran lubang.

\section{Hasil dan Pembahasan}

Jadi plastic viscosity ini adalah suatu tahanan terhadap aliran yang disebabkan oleh adanya gerakan-gerakan antara padatan-padatan didalam fluida, padatan cairan dan gesekan antara lapisan cairan. Plastic viscosity berupa garis antara pembacaan reading 600 dan 300 atau hasil torsi pada putaran $600 \mathrm{rpm}$ dikurangi torsi pada putaran $300 \mathrm{rpm}$. 


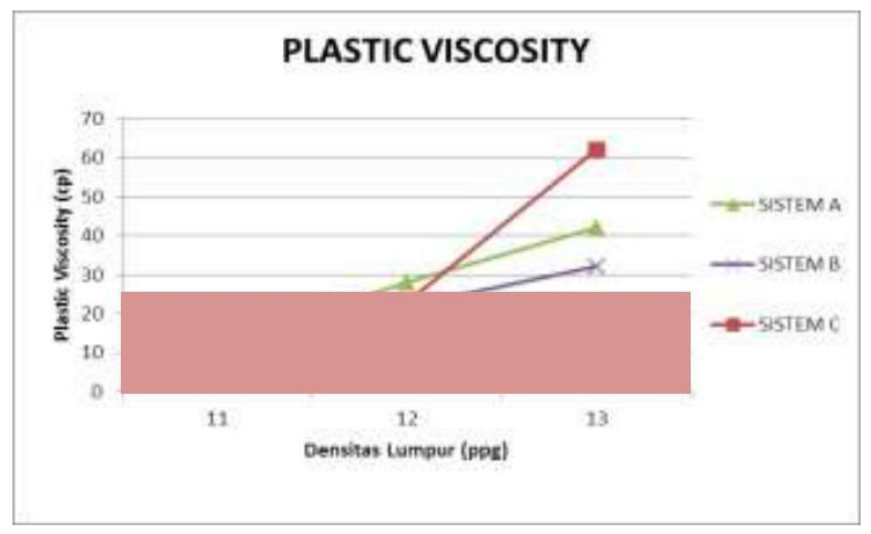

Hasilpenelitian darihargaPlastic Viscosity(PV) dilihat dari gambar grafik, pada sistem A mengalami peningkatan pada setiap konsentrasinya yaitu $12 \mathrm{cp}$ pada konsentrasi $11 \mathrm{ppg}$, $28 \mathrm{cp}$ pada konsentrasi $12 \mathrm{ppg}$, dan $42 \mathrm{cp}$ pada konsentrasi 13 ppg. Kenaikan Plastic Viscosity ini dipengaruhi oleh penambahan garam berat $\mathrm{CaNO}_{3}$ pada setiap konsentrasi. Sedangkan pada fluida komplesi sistem B juga mengalami peningkatan pada setiap konsentrasinya yaitu $13 \mathrm{cp}$ pada konsentrasi $11 \mathrm{ppg}, 22 \mathrm{cp}$ pada konsentrasi $12 \mathrm{ppg}$, dan $32 \mathrm{cp}$ pada konsentrasi $13 \mathrm{ppg}$. Harga Plastic Viscosity pada sistem A dan B jika dibandingkan mengalami penurunan pada konsentrasi yang sama, ini diakibatkan penambahan aditif Pac- $L$ pada sistem $B$ yang akan mempengaruhi pada sifat Rheologi dari fluida komplesi tersebut.

Pada sistem $C$ hasil yang yang didapat mengalami kenaikan yang cukup tinggi, yaitu 15 $\mathrm{cp}$ pada konsentrasi 11 ppg, $23 \mathrm{cp}$ pada konsentrasi $12 \mathrm{ppg}$, dan $63 \mathrm{cp}$ pada konsentrasi 13 ppg. Karena pada komposisi sitem $\mathrm{C}$ ini memiliki peningkatan yang cukup tinggi, ini dikarenakan perbedaan pada pemakaian solid pada sistem A dan B. Karena pada sistem $\mathrm{C}$ memakai kandungan solid yang meningkat pada setiap konsentrasi.

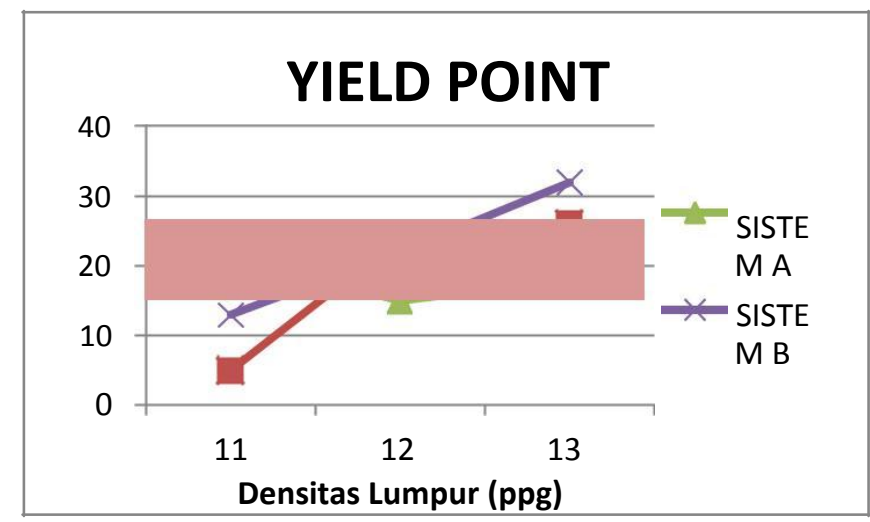

Yield Point merupakan bagian dari sifat rheology yang erat kaitannya dengan kemampuan fluida dalam membersihkan lubang sumur. YieldPoint (YP) untuk berbagai kandungan dari hasil percobaan tersebut dapat dilihat bahwa harga yield point dapat dilihat pada gambar grafik, yang mengalami penurunan pada sistem $A$ dan lebih memiliki harga yang setimbang dibanding sistem $B$, namun dengan dipakainya zat Pac- $L$ dan Pac-R pada campuran fluida $A$ maka harga penurunan yield point pun mengalami ketidakstabilan. Pada sistem fluida $A$ masih berkisar pada $18-21 \mathrm{lb} / 100 \mathrm{ft}^{2}$, maka tetap stabil walaupun masih terjadi perbedaan yang sangat besar pada komposisi yang lain. Tetapi kekuatan dalam pengangkatan sisa-sisa dari perforasi membutuhkan yield yang harusnya tinggi, sistem B tidak dapat digunakan karena masih dibawah standart. Sedangkan sistem C 
walaupun memiliki harga Yield Point sesuai specs, pada konsentrasi 13 ppg yang didapat yaitu $26 \mathrm{lb} / 100 \mathrm{ft}^{2}$ dan masih memiliki angka yang lebih tinggi dari specs, sedangkan pada konsentrasi $11 \mathrm{ppg}$ termasuk dalam specs tetapi memiliki nilai yang rendah, yang masuk dalam specs adalah konsentrasi pada 12 ppg yaitu $24 \mathrm{lb} / 100 \mathrm{ft}^{2}$.

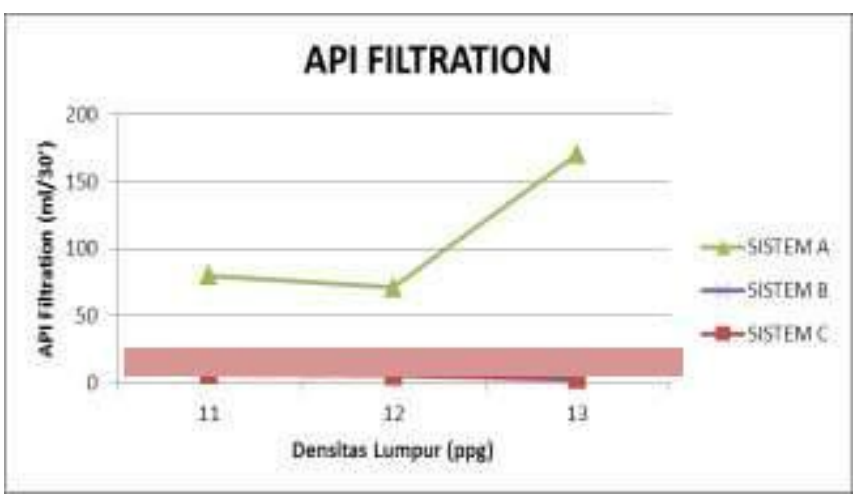

Hasil pengukuranlaju tapisanpadasistem A mengalami hasil yang sangat tinggi yaitu berkisar 80-170, sedangkan pada sistem B mengalami penrunan setelah ditambahkan Pac- $L$ sebagai pengontrol filtrat yaitu 5,6-18, pada sistem $C$ mengalami penurunan yang sangat tinggi setelah digunakannya komposisi $\mathrm{CaCO}_{3}$ yang ditambahkan komposisinya.

Setelah dilihat dari hasil percobaan, maka harga laju tapisan ideal diperoleh pada komposisi fluida C yaitu 4,2 ml/30' pada konsentrasi 12 ppg dengan penggunaan garam berat $\mathrm{NaNO}_{3}$, hal ini disebabkan karena penambahan material $\mathrm{CaCO}_{3}$ sebagai pemberat yang dapat menghambatnya filtrat masuk kedalam formasi dan termasuk kelebihan dari penggunaan garam berat nitrat yang tidak menyebabkan formation damage sehingga tidak mengganggu laju produksi seperti semula.

$\mathrm{CaCO}_{3}$ dapat mengatur laju tapisan suatu fluida agar tetap stabil $(<5 \mathrm{ml})$ sehingga mudah terkontrol, penambahan sebanyak $20 \mathrm{lb} / \mathrm{bbl} \mathrm{CaCO}_{3}$ pada komposisi fluida $\mathrm{A}$ dan $B$ dinilai tidak efisien dalam menanggulangi laju tapisan yang tidak terkontrol dari fluida, walaupun pada sistem fluida $A$ masih sangat tinggi dalam filtrat karena kurangnya material Pac-L serta $\mathrm{CaCO}_{3}$. Dalam penambahan HT-Stab juga sangat berpengaruh dalam perubahan suhu yang dilakukan untuk menstabilkan sifat fluida pada temperature tinggi.

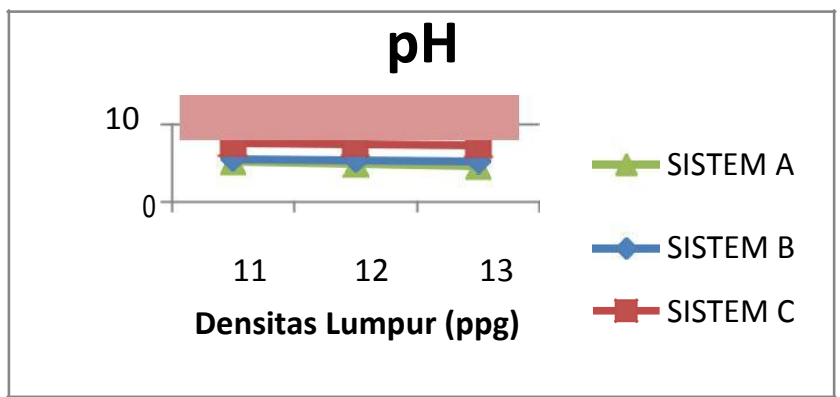


Pada sistem fluida A, B, maupun C. Derajat keasaman $(\mathrm{pH})$ fluida yang ideal sesuai dengan specs yang digunakan adalah beriksar antara 7-9, untuk itu pada komposisi fluida $\mathrm{B}$ dicampurkan $\mathrm{KOH}$ sebanyak $1 \mathrm{gr}$ untuk menaikan kadar $\mathrm{pH}$ yang semula turun pada sistem A.

Walaupun hasil pH masih kurang memenuhi, yang diakibatkan kandungan dari garam tersebut tetap tidak bisa diubah walaupun sudah ditambahkan $\mathrm{KOH}$. Sedangkan pada sistem $\mathrm{C}$ tidak ditambahkan $\mathrm{KOH}$ dikarenakan sebelum garam dimixing, garam tersebut diukur dan mempunyai derajat keasaman yang lebih tinggi dari sistem fluida $\mathrm{A}$ dan $\mathrm{B}$, sehingga tidak ditambahkannya $\mathrm{KOH}$ pada sistem ini. $\mathrm{pH}$ yang didapatkan pada sistem fluida $\mathrm{C}$ yaitu 7,5, 7,4, dan 7,3 pada setiap konsentrasi. Walaupun pada konsentrasi 11 ppg memiliki nilai yang lebih tinggi dibandingkan konsentrasi yang lain, akan tetapi pada konsentrasi 12 ppg memiliki hasil specs yang diinginkan pada setiap sifat fisik yang diujikan.

\begin{tabular}{|l|l|}
\hline Konsentrasi Sistem Fluida C (NaHNO) & Hasil Pengukuran Swellmeter \\
\hline $11 \mathrm{ppg}$ & $14,3 \%$ \\
\hline $12 \mathrm{ppg}$ & $6 \%$ \\
\hline $13 \mathrm{ppg}$ & $4,4 \%$ \\
\hline
\end{tabular}

Dikarenakan dilihat pada hasil yang terpenuhi dalam specs dan sesuai sebagai fluida komplesi, formulasi dari garam berat $\mathrm{NaNO}_{3}$ diukur dalam pengukuran swellmeter agar dapat dilihat jika fluida ini bertemu dengan lapisan shale atau bertemu dengan mineral clay tidak menyebabkan pengembangan. Setelah dites pada hasil swellmeter hasil yang terpenuhi adalah sistem fluida pada konsentrasi 12 ppg yaitu 6\%. Maka dari itu saat fluida ini bertemu dengan lapisan shale atau bertemu dengan mineral clay tidak akan menyebabkan pengembangan. Hasil tes swellmeter ini diteliti selama 24 jam agar dapat dilihat keefektifannya.

\section{Kesimpulan}

Berdasarkan hasil pembahasan yang telah disebutkan sebelumnya, didapat beberapa kesimpulan sebagai berikut :

1. Harga Plastic Viscosity dapat dipengaruhi oleh kandungan solid pada setiap komposisi sistem fluida. Semakin banyak kandungan solid yang digunakan, maka harga Plastic Viscosity akan semakin besar. Hasil yang sesuai dengan nilai Plastic Viscosity adalah sistem fluida A dengan konsentrasi $11 \mathrm{ppg}$ yaitu $12 \mathrm{cp}$, sistem fluida B pada konsentrasi $11 \mathrm{ppg}$ dan $12 \mathrm{ppg}$ yaitu $13 \mathrm{cp}$ dan $22 \mathrm{cp}$, dan terakhir pada fluida sistem $C$ pada konsentrasi 11 ppg dan 12 ppg yaitu $15 \mathrm{cp}$ dan $23 \mathrm{cp}$.

2. Pengukuran Yield Point sangat penting untuk melihat kemampuan fluida dalam mengangkat debris, hasil yang sesuai dengan specs yang digunakan adalah sistem fluida A pada semua konsentrasi yaitu 15-21 $\mathrm{lbs} / 100 \mathrm{ft}^{2}$, sistem fluida B tidak ada yang sesuai dengan specs, dan sistem $C$ hanya pada konsentrasi 12 ppg saja yang sesuai yaitu $24 \mathrm{lbs} / 100 \mathrm{ft}^{2}$.

3. Harga API Filtration yang sesuai dengan specs adalah fluida sistem $C$ dengan konsentrasi $12 \mathrm{ppg}$ dan $13 \mathrm{ppg}$ yaitu $4,2 \mathrm{ml} / 30^{\prime}$ dan $2,4 \mathrm{ml} / 30^{\prime}$ sedangkan fluida sistem lain tidak sesuai dengan specs yang diinginkan.

4. Pengukuran $\mathrm{pH}$ sangat penting agar tidak menyebabkan korosifitas pada peralatan yang digunakan. Hasil $\mathrm{pH}$ yang sesuai dengan ketentuan adalah $\mathrm{pH}$ pada sistem $\mathrm{C}$ pada setiap konsentrasinya yaitu 7,31-7.5. 
5. Pengukuran Swellmeter sangat penting agar tidak terjadinya pengembangan saat fluida komplesi bertemu dengan lapisan shale atau mineral clay. Harga Swellmeter yang sesuai adalah sistem $C$ pada konsentrasi 12 ppg dan 13 ppg yaitu 6\% dan $4 \%$.

6. Setelah dilakukan analisa dalam menentukan fluida komplesi yang sesuai dengan specs, dilihat dari sifat-sifat pada Yield Point, Plastic Viscosity, API Filtration, pH dan hasil Swellmeter, maka fluida komplesi yang memenuhi specs adalah fluida komplesi garam berat nitrat $\mathrm{NaNO}_{3}$ pada sistem $\mathrm{C}$ dengan densitas fluida $12 \mathrm{ppg}$.

\section{Daftar Pustaka}

Baroid; Completion Fluid; Baroid The Completes Fluids Company;----- ;

Burhanuddin A, M. Wijanarko, Anggoro; Low Solid - Non Damaging Drilling Fluid As Case Study In Kaji Semoga Horisontal Well; The Drilling \& Production Meeting VII; Yogyakarta; 2003.

Ruse Nitrates and Nitrites; Available from: http://www.inchem.org/nitrates\&nitrites.html; IPCS Newcastle, United Kingdom-1999; Access on: September 08, 2014

Sangka, Nataniel B; Evaluasi Lapangan Penggunaan Modified Phosphate Sebagai Completion Fluid Baru, Studi Kasus Sumur Eksplorasi KRE-01; Jakarta; 2008.

Sangka, Nataniel B; Kajian Teknis, Ekonomis dan Lingkungan CF Berbasis Phosphat; Workshop Drilling UTC; Jakarta-Indonesia; 2010.

Sangka, Nataniel B \& Hendra Budiman; New High Density Phosphate Based Completion Fluid A Case History of Exploration Wells: KRE-01, BOP-01, TBR-01 and KRT-01 In Indonesia, SPE LACPEC-10, Lima-Peru; 2010.

Sangka, Nataniel B, M. Syarief Hidayat \& Hendra Budiman; Succes Story: Reuse Application Of Phosphate Based Completion Fluid; SPE T \& T, Trinidad \& Tobago; 2014.

Suprayitno, Ilham, Penentuan Tend Permeabilitas Formasi Sandstone Terhadap CF Spesifik; Laboratorium Analisa batuan Reservoir Usakti; FT-Trisaksi, Jakarta; 2014.

Suprayitno, Ilham, Penentuan Tend Permeabilitas Formasi Sandstone (Batuan sandstone sintetik Berea) Terhadap CF Spesifik; Laboratorium Analisa batuan Reservoir Usakti; FT-Trisaksi, Jakarta; 2014.

Wardoyo, Haryanto; Cased History of PZ Brine In Rimau Block in Kaji Semoga Field, Medco Energy South Sumatera - Indonesia; PT. Medco Energy; Jakarta; 2003. 